
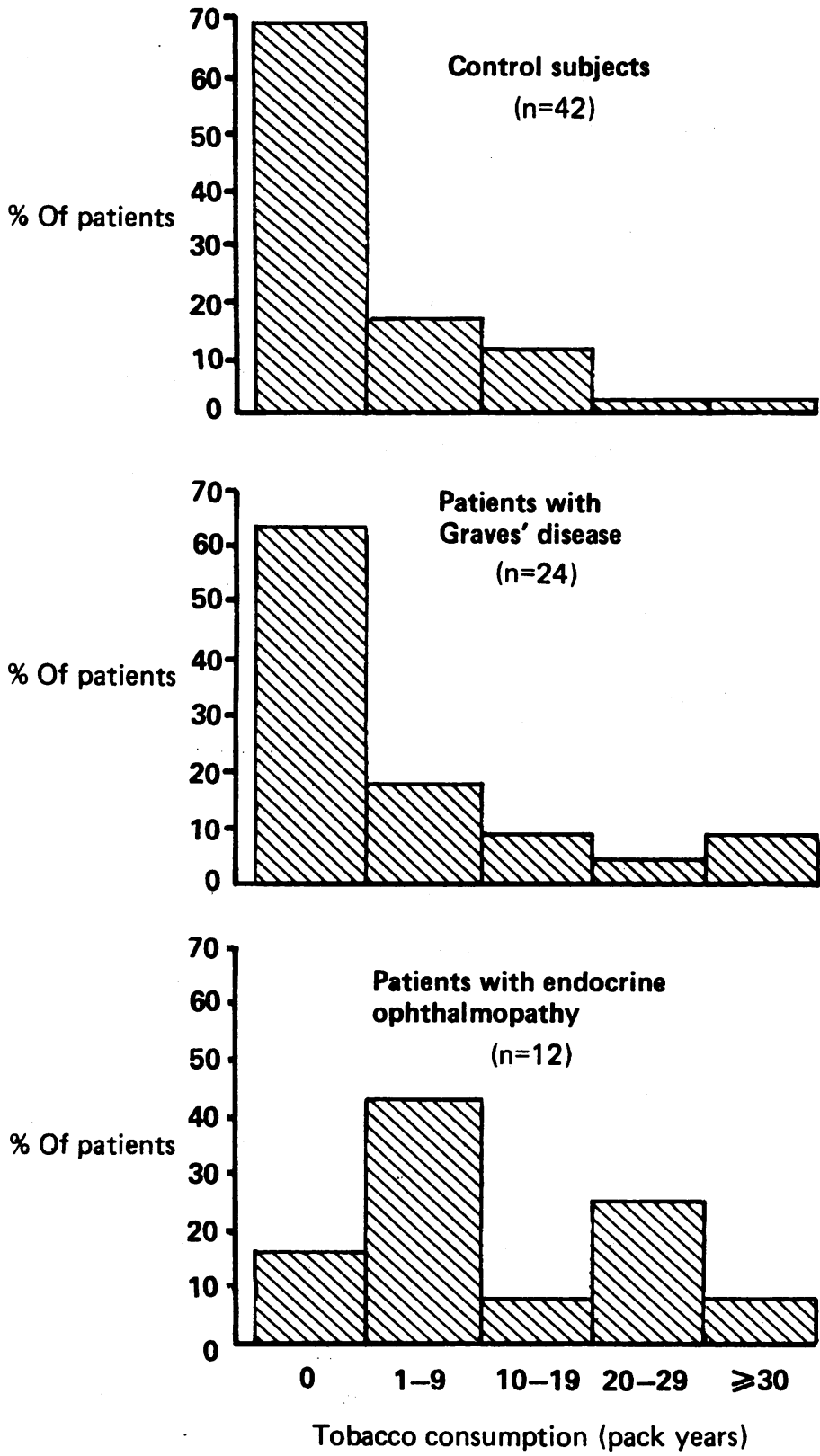

Relative distribution of total tobacco consumption in all subjects studied. Pack years were calculated as average daily consumption of cigarettes $(20) \times$ number of years of smoking. For pipe smokers daily amount of tobacco consumed was converted to corresponding number of cigarettes.

smoking, and this might explain the induction of severe eye disease in thyroid disorders.

This is the first study suggesting a direct relation between smoking and severe endocrine ophthalmopathy. We emphasise that the number of probands was small and that the investigation was initiated by the observation that some of them were smokers. Further studies should be performed to see whether smokers are overrepresented among patients with thyroid disease with severe ophthalmopathy. If a relation was found stopping smoking might have a beneficial effect in patients with eye disease associated with thyroid disorders.

This study was supported by a grant from the Swedish Tobacco Company. We thank Mr Lennarth Nyström, medical statistician, for advice and help with calculations.

1 Jacobson DH, Gorman CA. Endocrine ophthalmopathy: current ideas concerning etiology, pathogenesis, and

2 Werner SC. Modification of the classification of the eye changes of Graves' disease: recommendations of the ad hoc committee of the American Thyroid Association. $\mathcal{I}$ Clin Endocrinol Metab $1977 ; 44: 203-4$

3 Robins J, Greenland S, Breslow NE. A general estimator for the variance of the Mantel-Haenszel odds ratio. Am $\mathcal{F}$ Epidemiol 1986;124:719-23.
4 Christensen SB, Ericsson UB, Janzon L, Tibblin S, Melander A. Influence of cigarette smoking on goiter formation, thyroglobulin, and thyroid hormone levels in women. $\mathcal{J}$ Clin Endocrinol Metab 1984:58:615-8.

5 Miller LG, Goldstein G, Murphy M, Ginns LC. Reversible alterations in immunoregulatory T cells in smoking. Analysis by monoclonal antibodies and flow cytometry. Chest 1982;82:526-9.

(Accepted 5 fune 1987)

Department of Medicine, Umeå University Hospital, S-901 85 Umeå, Sweden E HÄGG, MD, senior lecturer in medicine

K ASPLUND, MD, senior lecturer in medicine

Correspondence to: Dr Hägg.

\section{Penetrating abdominal wound caused by a firework}

Penetrating abdominal wounds caused by fireworks are uncommon; we report a case.

\section{Case report}

On Guy Fawkes's day in 1986 during an organised firework display a rocket failed to ignite. It was removed from its holder and thrown on the ground. On impact it caught fire and veered horizontally into the crowd. It became lodged in the clothing of a 12 year old girl, and within seconds the explosion to release the "stars" occurred. Struggling to free herself from her burning clothes, the girl burnt both hands. She also suffered deep burns to the left side of her abdomen and chest and the anterior surface of her left forearm ( $5 \%$ of her total body surface area). Just below the costal margin there was a wound $4 \mathrm{~cm}$ long and $1 \mathrm{~cm}$ wide with charred edges, which was thought to be superficial (figure). Her genera condition was good, and she was admitted for observation.

Seven hours later her condition deteriorated. She complained of pain in her left iliac fossa and discomfort in her left shoulder. On re-examination there was rebound tenderness, guarding, and rigidity. The bowel sounds that had previously been present had disappeared. Her pulse, blood pressure, and temperature remained within normal limits. A second set of abdominal $x$ ray films showed free gas under the diaphragm.

At laparotomy the wound in the left hypochondrium penetrated not only the abdominal wall but also the stomach. Anteriorly at the junction of the fundus and body and posteriorly near the attachment of the lesser omentum, lying below the stomach, was a $2.5 \times 2.0 \mathrm{~cm}$ burn on the wall of the jejunum. A $2 \mathrm{~cm}$ laceration on the lower pole of the spleen was also found.

The gastric perforation was closed in two layers after excision of the charred edges of the wound. The laceration in the spleen was sutured, and the bleeding stopped. The burnt area of the jejunum was oversewn transversely with two layers of seromuscular sutures. The perforation in the abdominal wall was sutured from its deep surface, but the skin at the site of entry was left open. She made an uncomplicated recovery.

\section{Comment}

Fireworks used in displays are explosive or combustible. The rocket that caused this injury burns for from five to eight seconds and attains a

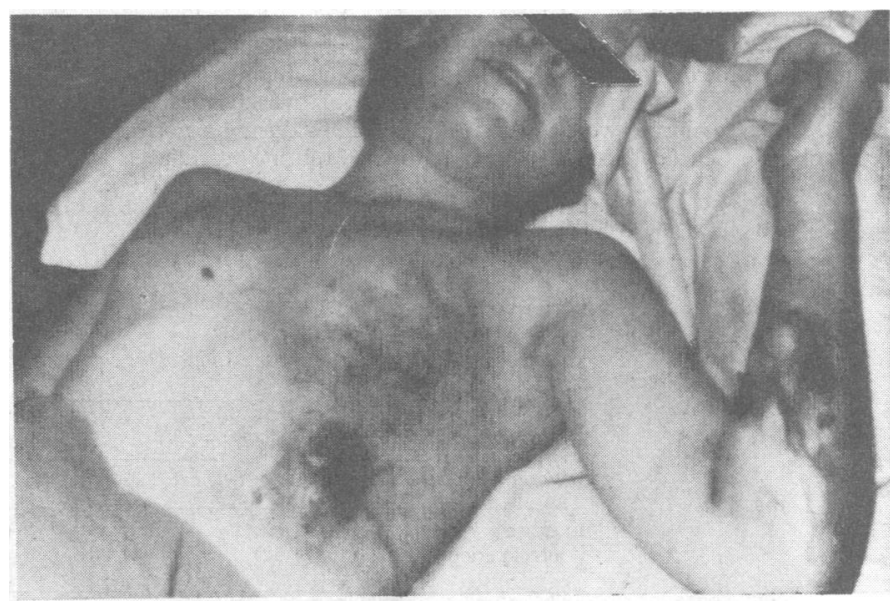

Patient on admission to casualty department. 
maximum height of $152-183 \mathrm{~m}$; it weighs $200 \mathrm{~g}$ and contains 65 stars of about $80 \mathrm{~g}$ total weight. The average thrust is $4.31 \mathrm{~kg}$. For a missile to perforate the skin and its underlying tissues a minimum velocity of around $70 \mathrm{~m} / \mathrm{s}$ is necessary with an energy per unit area of presentation of about $2 \cdot 1 \mathrm{~m} . \mathrm{kg} / \mathrm{cm}^{2} .^{2}$ In this case the rocket's projectile explosive force lodged it into the clothes or just under the skin (the upper end of the rocket being conical) and was superseded by the explosive force that released the stars; thus two complementing forces caused this injury. The extent of the injury has many factors, important ones being the mass, velocity, density, shape, and area of presentation of the missile and the distance traversed. Whatever the circumstance this size of rocket can cause severe bodily harm, which might even prove fatal.

We have been unable to find any report of a penetrating abdominal wound by a firework, although a penetrating sternal wound associated with a pneumomediastinum in a 10 year old boy who was struck by a plastic rocket ${ }^{3}$ and a penetrating bone wound resulting from a firework ${ }^{4}$ have been described. Fireworks will probably not be banned in the near future. The incidence of injuries can be further reduced by better organisation during displays. ${ }^{5}$ Displays should be supervised only by responsible adults who are fully aware of the potential dangers. Any firework that fails to fire should not be touched but should be doused with water.

We thank Mr J Gowar, consultant plastic surgeon, for his help.

1 DiMaio VJM. Penetration and perforation of skin by bullets and missiles. A review of the literature. Am f Forensic Med Pathol 1981;2:107-10.

2 DiMaio VJM, Copeland AR, Besant-Matthews PE, Fletcher LA, Jones A. Minimal velocities necessary for perforation of skin by air gun pellets and bullets. J Forensic Sci 1982;27:894-8.

3 Matsumura C. A rare case of penetrated sternal wound with pneumomediastinum due to fireworks. Japanese foumal of Thoracic Surgery 1981;34:59-61.

4 Garden OJ, Morris EW, Young AB. A penetrating wound of bone resulting from a firework. British Joumal of Accident Surgery 1983;15:167-9.

5 Jackson D. Injuries from firework. Br Med $\mathcal{f} 1961 ;$ ii:1184-7.

(Accepted 29 June 1987)

Birmingham Accident Hospital, Birmingham B15 1NA

M S SHAKIL, MB, FRCS, registrar, trauma

J E M SMITH, FRCS, consultant surgeon

Correspondence to: Mr M S Shakil, Basildon Hospital, Basildon, Essex SS16 5NL.

\section{Leucocytosis induced by exercise}

Exercise induces an immediate leucocytosis, its magnitude being proportional to the intensity of work and duration of exercise, ${ }^{1}$ although a given workload causes a greater leucocytosis in unconditioned subjects than trained athletes. ${ }^{2}$ We report the effects of 30 minutes' vigorous exercise in healthy male volunteers.

\section{Subjects, methods, and results}

We studied 10 healthy white men (mean age $42 \cdot 5$, range $26-52$ ) who continued their usual daily routine for 24 hours before the study but avoided strenuous exercise. For the study each man exercised at a rate close to his maximum for 30 minutes between 1000 and 1100 , swimming about $1 \mathrm{~km}$, playing squash, or jogging roughly $6 \mathrm{~km}$ (13 sessions altogether (five jogging, four squash, and four swimming): nine men did one each and one did four). Blood samples were taken immediately before and after exercise and at intervals over the next five and a half hours. Control samples were taken at similar times during a normal working (control) day. Leucocyte counts were measured by routine procedures.
Counts in control samples were within the normal range except for one that was slightly low. During the control day leucocyte numbers increased slightly (table). Immediately after $\mathbf{3 0}$ minutes' exercise the mean leucocyte count had risen to $115 \%$, but by one hour it had fallen to $104 \%$ compared with mean control counts $(=100 \%)$. These mean values, however, hid considerable individual variation. In cight subjects exercise caused a small immediate increase in leucocyte numbers; at one hour the count had fallen to baseline in four men but remained the same or had even increased in the others. The two other subjects had an immediate slight decrease in leucocyte numbers, which persisted until one hour. Irrespective of the immediate effect a delayed and prolonged leucocytosís that reached a peak between two and four hours was noted in all subjects; this was predominantly due to a rise in neutrophils. The leucocyte count did not exceed the upper limit of normal immediately after exercise in any of the subjects, but it did do so during the delayed leucocytosis in six of the 13 sessions (done by four of the 10 subjects). The magnitude of the delayed leucocytosis (mean $175 \%, n=13$ ) varied greatly among subjects (range 112-235\%) when compared with control values before exercise $(=100 \%)$. It was unrelated to the type of exercise but was most pronounced in subjects who took a little or no regular exercise.

\section{Comment}

Our results show that a short period of vigorous recreational exercise can induce a substantial delayed leucocytosis; this seems to have been overlooked previously because samples were not taken at appropriate times. Interestingly, a polymorph leucocytosis of extremely variable degree that occurred some hours after 10 minutes' exercise was noted in one study of lymphocyte subpopulations but not investigated further. ${ }^{3}$ A biphasic leucocyte response, similar to that reported here, was noted after administration of adrenaline. ${ }^{4}$ We suggest that adrenaline released during exercise causes a small immediate leucocytosis in most people by its direct effect, on leucocyte demargination. The second, delayed leucocytosis may occur because cortisol acts subsequently to release leucocytes from the bone marrow. ${ }^{5}$

Sports aimed at maintaining cardiovascular fitness are becoming increasingly popular; it is therefore important to know both the long and short term effects of exercise on variables measured routinely in clinical practice. Further studies are needed to determine how age, sex, workload and duration of exercise, and physical fitness might affect the magnitude of the delayed leucocytosis induced by exercise and to elucidate the mechanisms. Caution is clearly needed when interpreting the importance of a raised leucocyte count in samples taken within a few hours of even short periods of moderately vigorous exercise.

1 Gary WE, Bryan WR. Variations in white blood cell counts. Physiol Rev 1935;15:597-638 2 Hanson PG, Flaherty DK. Immunological responses to training in conditioned runners. $\mathrm{Clin} \mathrm{Sci}$ 1981;60:225-8.

3 Steel CM, Evans J, Smith MA. Physiological variation in circulating B cell:T cell ratio in man. Nature 1974;247:387-8.

4 Samuels AJ. Primary and secondary leucocyte changes following intramuscular injection of epinephrine hydrochloride. J Clin Invest 1951;30:941-7.

5 Moorthy AV, Zimmerman SW. Human leucocyte responses to an endurance run. Eur $\mathcal{J}$ Applied Physiol 1978;38:271-6.

(Accepted 26 fune 1987)

School of Biological Sciences, Queen Mary.College, London E1 4NS

D A MCCARTHY, BSC, PHD, lecturer in immunology

Department of Rheumatology, The London Hospital, London E1 1BB

J D PERRY, FRCP, consultant rheumatologist

R D MELSOM, MB, MD, senior registrar in rheumatology

Department of Pharmacology, University College, London WC1E 6BT

M M DALE, MB, PHD, senior lecturer in pharmacology

Correspondence to: Dr McCarthy.

Effect of half an hour of exercise on leucocyte count $\left(\times 10^{9} / l\right)$. Results are the means of 13 experiments $(S D)$

\begin{tabular}{|c|c|c|c|c|c|c|}
\hline & \multirow[b]{2}{*}{ Baseline } & \multicolumn{5}{|c|}{ Time (h) after start of exercise } \\
\hline & & $1 / 2$ & 1 & $23 / 4$ & $4 \frac{1}{2}$ & 6 \\
\hline $\begin{array}{l}\text { Exercise } \\
\text { Control periods }\end{array}$ & $\begin{array}{l}5.97(2.02)^{\star} \ddagger \\
6.68(1.52)\end{array}$ & $\begin{array}{l}7.45(1.45) \ddagger \\
6.49(1.50)\end{array}$ & $\begin{array}{l}6.97(1.74) \\
6.73(1.50)\end{array}$ & $\begin{array}{c}10.45(3.27)^{\star} \dagger \\
6.83(1.47) \dagger\end{array}$ & $\begin{array}{r}10.00(3.05) \\
7.02(1.36)\end{array}$ & $\begin{array}{l}8 \cdot 83(2.67) \\
7 \cdot 19(1.55)\end{array}$ \\
\hline
\end{tabular}

By paired $t$ tests the difference between these two counts was significant: ${ }^{\star} p<0.01 ; \nmid p<0.01 ; \neq p<0.05$.

§Random activity. 